\section{Visualizing endocytotic pathways at transmission electron microscopy via diaminobenzidine photo- oxidation by a fluorescent cell-membrane dye}

\section{S. Grecchi, M. Malatesta}

Department of Neurological and Movement Sciences, Anatomy and Histology Section, University of Verona, Italy

\section{Abstract}

The endocytotic pathway involves a complex, dynamic and interacting system of intracellular compartments. PKH26 is a fluorescent dye specific for long-lasting cell membrane labelling which has been successfully used for investigating cell internalization processes, at either flow cytometry or fluorescence microscopy. In the present work, diaminobenzidine photo-oxidation was tested as a procedure to detect PKH26 dye at transmission electron microscopy. Our results demonstrated that DAB photo-oxidation is a suitable technique to specifically visualise this fluorescent dye at the ultrastructural level: the distribution of the granular dark reaction product perfectly matches the pattern of the fluorescence staining, and the electron density of the fine precipitates makes the signal evident and precisely detectable on the different subcellular compartments involved in the plasma membrane internalization routes.

\section{Introduction}

In eukaryotic cells the endocytotic pathway involves a complex and dynamic system of intracellular compartments responsible for internalization, transport, sorting and degradation of macromolecules. ${ }^{1}$ Many histochemical techniques have been applied to elucidate the endocytotic pathway in various experimental models..$^{2-5}$ In particular, photo-oxidation of diaminobenzidine (DAB) with fluorescent dyes (which allows to combine light and transmission electron microscopy by detecting fluorescent molecules at the ultrastructural level) significantly contributed to elucidate endocytosis dynamics. ${ }^{6-11}$

DAB photo-oxidation is, in fact, a procedure capable to transform the unstable fluorescent signal of a wide variety of fluorochromes into a stable product: the free oxygen radicals originating from fluorochrome irradiation induce the local oxidation of DAB which gives rise to finely granular electron-dense precipitates whose contrast may be enhanced by osmium treatment. ${ }^{12-15}$ Due to the very short half-life (from $1 \mathrm{~ns}$ to $1 \mu \mathrm{s}$ ) of oxidizing chemical species, their spatial mobility is limited to a few nanometers, so that oxidized DAB gives rise to precipitates in very close proximity to the fluorochrome,${ }^{16}$ making DAB photo-oxidation a high sensitive method to detect in situ fluorescent molecules precisely, even if present in low amounts. ${ }^{17}$ In addition, DAB photooxidation can be associated with techniques of fluorescence recovery after photobleaching (FRAP), ${ }^{18}$ or adapted for confocal laser scanning microscopy ${ }^{19}$ or post-embedding immunocytochemistry, ${ }^{20}$ thus increasing its potential for in situ studies.

PKH26 (Sigma-Aldrich, St. Louis, M0, USA) is a fluorescent dye specific for cell membrane labelling which has been successfully used for investigating, at either flow cytometry or fluorescence microscopy, macrophage phagocytosis, ${ }^{21-26}$ virus absorption, ${ }^{27}$ and nanoparticle internalization. ${ }^{28,29}$ Since PKH26 allows a specific and long-lasting labelling of the plasma membrane at fluorescence microscopy, in the present work we tested the suitability of DAB photo-oxidation to visualise the subcellular organelles involved in the plasma membrane internalization routes at transmission electron microscopy.

\section{Materials and Methods}

\section{Cell culture and treatments}

Human HeLa cells (ATCC, Rockville, MD, USA) were grown in Dulbecco's minimal essential medium supplemented with $10 \%$ fetal bovine serum, $1 \%$ glutamine, $100 \mathrm{U}$ of penicillin and streptomycin (Celbio S.r.l., Milan, Italy), in a humidified air atmosphere containing 5\% $\mathrm{CO}_{2}$. Cells were seeded onto glass coverslips in six-multiwell plates $\left(1 \times 10^{5}\right.$ per well $) 48 \mathrm{~h}$ before being incubated with PKH26 Red Fluorescent Cell Linker Kit for General Cell Membrane Labeling (Sigma-Aldrich, Catalog Nos. MINI26 and PKH26GL) to stain the plasma membrane. After staining according to manufacturer's recommendations, the medium containing PKH26 dye was removed and replaced with fresh medium. The cells were observed as fresh preparations by fluorescence microscopy or processed for transmission electron microscopy (see below) either immediately after staining or after $30 \mathrm{~min}, 1 \mathrm{~h}$ and $3 \mathrm{~h}$.

Some cells were stained in suspension with PKH26 and immediately observed as fresh preparations by fluorescence microscopy.
Correspondence: Manuela Malatesta, Department of Neurological and Movement Sciences, Anatomy and Histology Section, University of Verona, Strada Le Grazie 8, 37134 Verona, Italy.

E-mail: manuela.malatesta@univr.it

Key words: Endocytosis, PKH26 dye, diaminobenzidine photo-oxidation, transmission electron microscopy.

Acknowledgments: Confocal fluorescence micrographs were taken at the "Centro Grandi Strumenti" of the University of Pavia (http:/cgs. unipvit).

Received for publication: 2 September 2014 Accepted for publication: 25 September 2014

This work is licensed under a Creative Commons Attribution NonCommercial 3.0 License (CC BYNC 3.0).

(OC) Copyright S. Grecchi and M. Malatesta, 2014 Licensee PAGEPress, Italy

European Journal of Histochemistry 2014; 58:2449 doi:10.4081/ejh.2014.2449

\section{Fluorescence microscopy}

Confocal laser scanning microscopy was performed with a Leica TCS-SP system mounted on a Leica DMIRBE inverted microscope using a $\mathrm{He} / \mathrm{Ne}$ laser at 543 for excitation. Spaced $(0.5 \mu \mathrm{m})$ optical sections were recorded using a Leica oil-immersion objective (63X; NA 3.2). Images were collected in the $1024 \mathrm{x}$ 1024 pixels format, stored on a magnetic mass memory and processed by the Leica Confocal Software.

\section{Transmission electron microscopy}

PKH26 stained HeLa cells on coverslips were fixed with $2.5 \%(\mathrm{v} / \mathrm{v})$ glutaraldehyde and $2 \%$ (v/v) paraformaldehyde in $0.1 \mathrm{M}$ phosphate buffer, $\mathrm{pH} 7.4$, at $4^{\circ} \mathrm{C}$ for $1 \mathrm{~h}$, washed and incubated with 3,3' diaminobenzidine (DAB) (20 $\mathrm{mg} / 10 \mathrm{~mL}$ in $0.05 \mathrm{M}$ Tris $\mathrm{HCl}, \mathrm{pH}$ 7.6) under simultaneous irradiation with two 8W 0sram Blacklite 350 lamps for $2 \mathrm{~h}$ at room temperature. These lamps have two emission peaks of high intensity at 550 and $580 \mathrm{~nm}$, thus being compatible with the excitation maximum (551 $\mathrm{nm})$ of PKH26 dye. The cells were then postfixed with $1 \% \mathrm{OsO}_{4}$ at room temperature for $1 \mathrm{~h}$, dehydrated with acetone and embedded in Epon. As controls, some PKH26 stained cells were processed as described above but omitting either DAB incubation or exposure to light; in addition, unstained cells were exposed to DAB incubation and/or exposure to light.

Thin sections were weakly stained with either $2.5 \%$ aqueous solution of uranyl acetate for $1-2 \mathrm{~min}$ or $2.5 \%$ to $5 \%$ aqueous solution of gadolinium triacetate for 10 min (gadolinium triacetate is a good substitute for uranyl 
acetate to enhance contrast of osmicated samples $^{30}$ ). The sections were observed in a Philips Morgagni transmission electron microscope (FEI Company) operating at $80 \mathrm{kV}$ and equipped with an Olympus Megaview II camera for digital image acquisition.

\section{Results and Discussion}

At confocal microscopy, the HeLa cells stained in suspension with the PKH26 dye showed a marked fluorescent labelling at the cell periphery, where numerous fluorescing membrane protrusions were clearly visible (Figure $1 \mathrm{a}, \mathrm{b}$ ). No signal was detected inside the cells, probably due to the reduced endocytotic activity of detached HeLa cells in suspension as much as it occurs in mitotic cells. ${ }^{31}$ When PKH26 dye was applied to HeLa cells adhering to the glass coverslips, a marked labelling was visible both at the periphery and inside the cells: the cell membrane was evident as a continuous fluorescent rim, while many fluorescent spots of different size and intensity were present throughout the cytoplasm (Figure $1 \mathrm{c}, \mathrm{d})$. No fluorescent signal was ever observed inside the cell nucleus. The membrane internalization was so rapid and massive that the amount of cytoplasmic spots was apparently similar between $30 \mathrm{~min}$ and $3 \mathrm{~h}$.

DAB photo-oxidation allowed to detect the fluorescent signal of PKH26 dye at transmission electron microscopy as fine granular electron-dense precipitates, and to specifically identify the structural components involved in the intracellular pathways of cell membrane internalization. At short times after PKH26 dye treatment most cells showed the fine dark reaction product diffusely distributed along their plasma membrane, including the fingerlike protrusions observed at fluorescence microscopy (Figure 2a). Many small invaginations containing the photo-oxidation precipitates were observed along the plasma membranes, and several labelled small vesicles were found just beneath the cell surface (Figure 2 b,c). These findings clearly depict successive steps of the plasma membrane internalization process and early endosome formation. At longer times after PKH26 staining, the DAB photo-oxidation product was mostly found inside multivesicular bodies and multilamellar bodies ubiquitously distributed in the cytoplasm, even very close to the nuclear envelope (Figure $2 \mathrm{~d}-\mathrm{f}$ ).

Multivesicular bodies are morphologically distinctive late endosomes filled with small luminal vesicles originating form invaginations of the endosomal membrane. They play a key role in the transport dynamics between the plasma membrane, the secretory pathway and
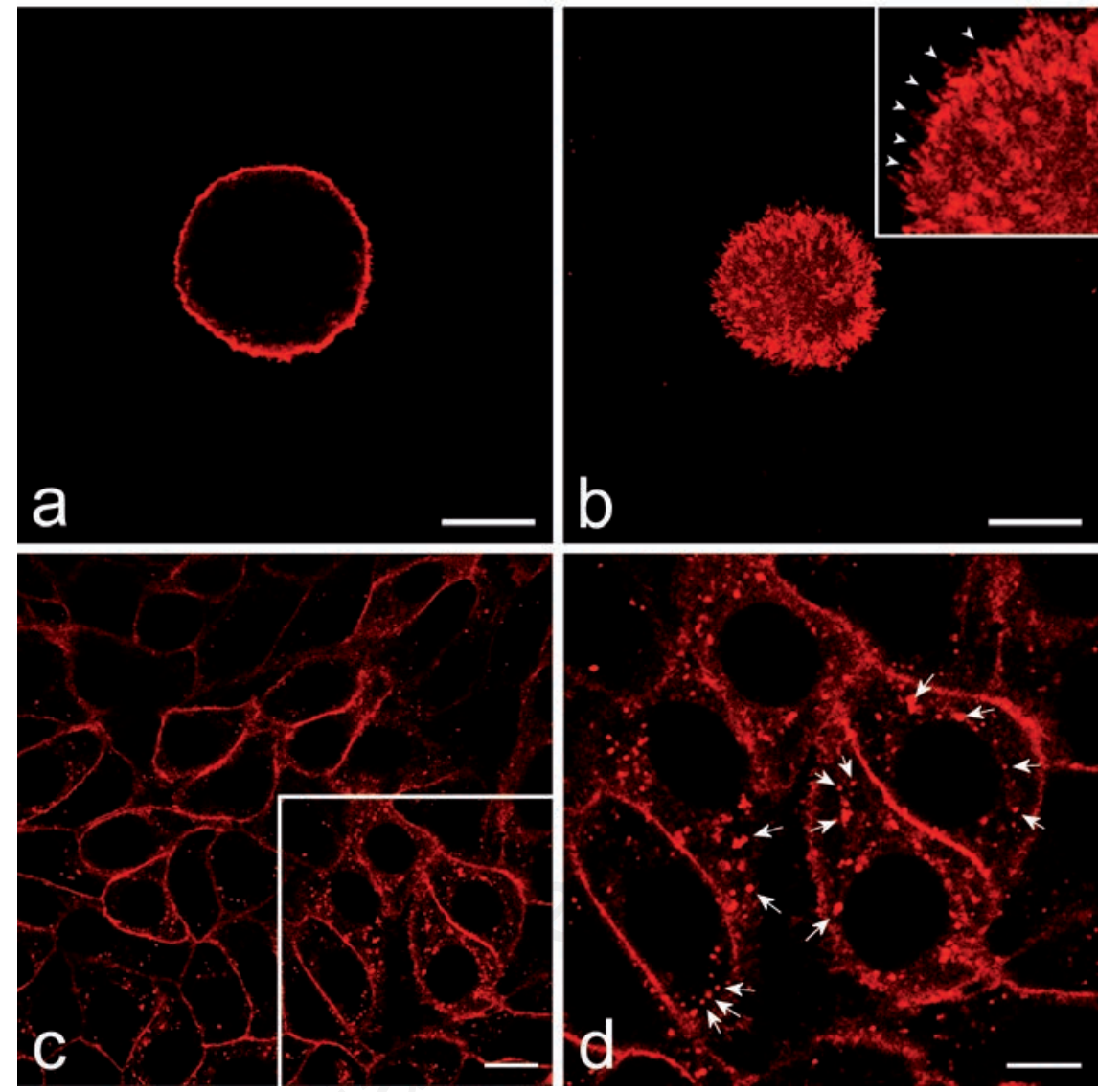

Figure 1. Confocal optical sections of HeLa cells; the labelling with red fluorescing PKH26 was performed on cells either in suspension $(a, b)$ or adhering to the glass coverslip (c,d). a) Equatorial optical section of a HeLa cell showing the plasma membrane labelling. b) Superficial optical section of the same cell whose tiny membrane protrusions are also finely labelled (arrowheads in the inset). The plasma membrane fuorescence is apparent as well after labelling of adhering cells (c) in which brightly fluorescing spots are also present inside the cytoplasm. d) The higher magnification of the frame in c allows a better visualization of the intracellular fluorescing spots (arrows). Scale bars: $20 \mu \mathrm{m}$.

the lysosomes; in particular, they incorporate transmembrane proteins and lipids as well as cytoplasmic material in the luminal vesicles that may be then either delivered to lysosomes for degradation, or released by exocytosis or stored in the cytoplasm. ${ }^{32}$ Thus, the central position of multivesicular bodies in the endocytotic pathway accounts for the presence of the photo-oxidated DAB in their intraluminal vesicles.

Multilamellar bodies represent lipid storage/secretory organelles that have been described in a plethora of physiological and pathological conditions characterized by defective lipid metabolism and/or autophagic activities. ${ }^{33}$ In our experimental model it is likely that PKH26 dye, which is stably incorporated with its long aliphatic tails into the lipid regions of the cell membranes, may interfere with the metabolism of phospholipids that accumulate in lysosomes by the endocytotic process. Similarly, many amphipathic drugs induce abnormal accumulation of multilamel- lar bodies either by forming indigestible druglipid complexes or by interfering directly with the lysosomal enzymes. ${ }^{33}$ No DAB precipitates were ever found free in the cytoplasm or inside the cell nuclei, thus confirming the durable linking of PKH26 dye to the plasma membrane (as reported in the manufacturer's technical datasheet) and to cell-membrane-derived organelles. Control samples never showed DAB precipitates (not shown). In order to facilitate the visualization of the DAB photo-oxidation product, the ultrathin sections were observed by omitting any additional staining, the mere osmication providing sufficient contrast to clearly distinguish all cellular organelles. In fact, even a weak staining with uranyl acetate masked the finest granular deposits (not shown), while staining with gadolinium triacetate did not improve DAB precipitate visualization (Supplementary Figure 1). On the other hand, lead citrate staining was unsuitable due to its tinily granular appearance ${ }^{34}$ which may mimic the photo-oxidation product. 


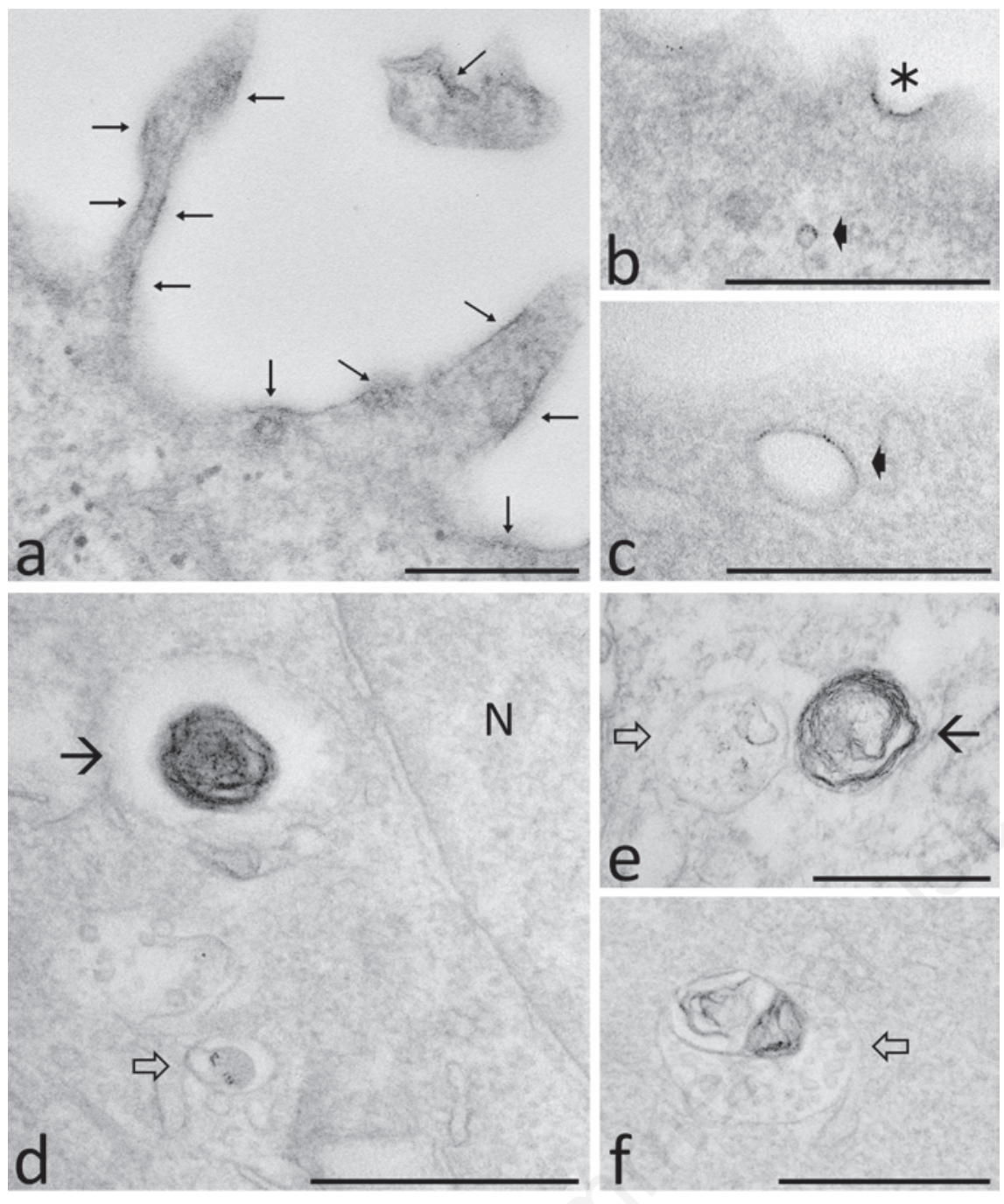

Figure 2. Transmission electron micrographs of HeLa cells at different times after PKH26 staining; DAB photo-oxidation. a) Immediately after PKH26 treatment a fine granular photo-oxidation product diffusely borders the cell surface (thin arrows). b,c) Thirty min after PKH26 staining, many invaginations of the cell membrane (asterisk) as well as small endocytotic vesicles (arrowheads) just beneath cell surface show the photo-oxidation reaction product. d-f) After one-three h after PKH26 staining, photo-oxidation precipitates are evident in many multivesicular bodies (open arrows) as well as in multilamellar bodies inside autophagic vacuoles (arrows). These vacuolar structures often occur near the cell nucleus $(\mathrm{N})$. Scale bars: $500 \mathrm{~nm}$.

DAB-photo-oxidation thus proved to be a suitable technique to specifically visualize at ultrastructural level the PKH26 red fluorescent dye for cell membrane labelling: the distribution of the granular dark reaction product precisely matches that of the fluorescing staining and the electron density of the fine precipitates makes the signal evident and precisely detectable in the different subcellular compartments. Future application of this technique may be foreseen for investigating, at the high resolution of electron microscopy, endosome or exosome dynamics under physiological or experimental conditions.

\section{References}

1. Di Fiore PP, von Zastrow M. Endocytosis, signaling, and beyond. Cold Spring Harb Perspect Biol 2014;6 pii: a016865.

2. Lakadamyali M, Rust MJ, Zhuang X. Endocytosis of influenza viruses. Microbes Infect 2004;6:929-36.

3. Panzeri D, Lavazza T, Malgaroli A. Advanced tracer techniques to monitor synaptic activity. Arch Ital Biol 2005; 143:157-68.

4. de Souza W, Sant'Anna C, Cunha-e-Silva
NL. Electron microscopy and cytochemistry analysis of the endocytic pathway of pathogenic protozoa. Prog Histochem Cytochem 2009;44:67-124.

5. Bissig C, Johnson S, Gruenberg J. Studying lipids involved in the endosomal pathway. Methods Cell Biol 2012;108:19-46.

6. Fomina AF, Deerinck TJ, Ellisman MH, Cahalana MD. Regulation of membrane trafficking and subcellular organization of endocytic compartments revealed with FM1-43 in resting and activated human T cells. Exp Cell Res 2003;291:150-66.

7. Liu TT, Kishimoto T, Hatakeyama H, Nemoto T, Takahashi N, Kasai $\mathrm{H}$. Exocytosis and endocytosis of small vesicles in PC12 cells studied with TEPIQ (two-photon extracellular polar-tracer imaging-based quantification) analysis. J Physiol 2005;568(Pt 3):917-29.

8. LoGiudice L, Sterling P, Matthews G. Vesicle recycling at ribbon synapses in the finely branched axon terminals of mouse retinal bipolar neurons. Neurosci 2009;164:1546-56.

9. Meunier FA, Nguyen TH, Colasante C, Luo F, Sullivan RK, Lavidis NA, et al. Sustained synaptic-vesicle recycling by bulk endocytosis contributes to the maintenance of high-rate neurotransmitter release stimulated by glycerotoxin. J Cell Sci 2010; 123(Pt 7):1131-40.

10. Schikorski T. Monitoring rapid endocytosis in the electron microscope via photoconversion of vesicles fluorescently labeled with FM1-43. Methods Mol Biol 2010; 657:329-46.

11. Kukulski W, Schorb M, Welsch S, Picco A, Kaksonen M, Briggs JAG. Correlated fluorescence and 3D electron microscopy with high sensitivity and spatial precision. $\mathrm{J}$ Cell Biol 2011;192:111-9.

12. Maranto AR. Neuronal mapping: a photooxidation reaction makes lucifer yellow useful for electron microscopy. Science 1982;217:953-5.

13. Sandell JH, Masland RH. Photoconversion of some fluorescent markers to a diaminobenzidine product. J Histochem Cytochem 1988;36:555-9.

14. Lubke J. Photoconversion of different fluorescent substances for light and electron microscopy. Neurosci Protocols 1993;50: 601-13.

15. Singleton CD, Casagrande VA. A reliable and sensitive method for fluorescent photoconversion. J Neurosci Meth 1996;64: 47-54.

16. Karuppanapandian T, Moon JC, Kim C, Manoharan K, Kim W. Reactive oxygen species in plants: their generation, signal transduction, and scavenging mechanisms. Aust J Crop Sci 2011;5:709-25. 
17. Pellicciari C, Giagnacovo M, Cisterna B, Costanzo M, Croce AC, Bottiroli G, et al. Ultrastructural detection of photosensitizing molecules by fluorescence photoconversion of diaminobenzidine. Histochem Cell Biol 2013;139:863-71.

18. Darcy KJ, Staras K, Collinson LM, Goda Y. An ultrastructural readout of fluorescence recovery after photobleaching using correlative light and electron microscopy. Nat Protoc 2006;1:988-94.

19. Colello RJ, Tozer J, Henderson SC. Confocal laser scanning microscopic photoconversion: a new method to stabilize fluorescently labeled cellular elements for electron microscopic analysis. Curr Protoc Neurosci 2012; Chapter 2:Unit2.15.

20. Malatesta M, Zancanaro C, Costanzo M, Cisterna B, Pellicciari C. Simultaneous ultrastructural analysis of fluorochromephotoconverted diaminobenzidine and gold immunolabelling in cultured cells. Eur J Histochem 2013;57:e26.

21. Bratosin D, Mazurier J, Slomianny C, Aminoff D, Montreuil J. Molecular mechanisms of erythrophagocytosis: flow cytometric quantitation of in vitro erythrocyte phagocytosis by macrophages. Cytometry 1997;30:269-74.

22. Bratosin D, Mazurier J, Tissier JP, Slomianny C, Estaquier J, Russo-Marie F, et al. Molecular mechanisms of erythrophagocytosis. Characterization of the senescent erythrocytes that are phagocytized by macrophages. C R Acad Sci III-Vie 1997;320:811-8.

23. Pricop L, Salmon JE, Edberg JC, Beavis AJ. Flow cytometric quantitation of attachment and phagocytosis in phenotypically-defined subpopulations of cells using PKH26labeled Fc gamma R-specific probes. J Immunol Methods 1997;205:55-65.

24. Williams JM, Colman R, Brookes CJ, Savage C0, Harper L. Anti-endothelial cell antibodies from lupus patients bind to apoptotic endothelial cells promoting macrophage phagocytosis but do not induce apoptosis. Rheumatology (Oxford) 2005;44:879-84.

25. Swan R, Chung CS, Albina J, Cioffi W, Perl $\mathrm{M}$, Ayala A. Polymicrobial sepsis enhances clearance of apoptotic immune cells by splenic macrophages. Surgery 2007;142: 253-61.

26. Healey G, Veale MF, Sparrow RL. A fluorometric quantitative erythrophagocytosis assay using human THP-1 monocytic cells and PKH26-labelled red blood cells. J Immunol Methods 2007;322:50-6.

27. Balogh A, Pap M, Markó L, Koloszár I, Csatáry LK, Szeberényi J. A simple fluorescent labeling technique to study virus adsorption in Newcastle disease virus infected cells. Enzyme Microb Technol 2011;49:255-9.

28. Malatesta M, Giagnacovo M, Costanzo M,
Conti B, Genta I, Dorati R, et al. Diaminobenzidine photoconversion is a suitable tool for tracking the intracellular location of fluorescently labelled nanoparticles at transmission electron microscopy. Eur J Histochem 2012;56:e20.

29. Malatesta M, Pellicciari C, Cisterna B, Costanzo M, Galimberti V, Biggiogera M, et al. Tracing nanoparticles and photosensitizing molecules at transmission electron microscopy by diaminobenzidine photooxidation. Micron 2014;59C:44-51.

30. Nakakoshi M, Nishioka H, Katayama E. New versatile staining reagents for biological transmission electron microscopy that substitute for uranyl acetate. J Electron Microsc (Tokyo) 2011;60:401-7.

31. Fielding AB, Royle SJ. Mitotic inhibition of clathrin-mediated endocytosis. Cell Mol Life Sci 2013;70:3423-33.

32. Hanson PI, Cashikar A. Multivesicular body morphogenesis. Annu Rev Cell Dev Biol 2012;28:337-62.

33. Schmitz G, Muller G. Structure and function of lamellar bodies, lipid-protein complexes involved in storage and secretion of cellular lipids. J Lipid Res 1991;32:1539-70.

34. Mollenhauer HH. Contamination of thin sections: Some observations on the cause and elimination of "embedding pepper". J Electron Microsc Tech 1987;5:59-63. 